\title{
O MÉTODO DE ESQUIVA RAWLSIANO COMO CONSENSO CÉTICO
}

\author{
Dalton Franco*
}

Resumo: O artigo discute o método de esquiva de John Rawls em A ideia de um consenso por justaposição, de 1987. O centro da leitura que oferecemos sobre o argumento do consenso informa a recusa injustificada do ceticismo, a segunda objeção. Sugere-se que ele pode integrar o consenso por sobreposição. Deseja-se apontar para um fato conhecido entre os céticos: o método de oposições para a discussão configura uma ética do público para o público. Descrevese como a linguagem fenomênica pode atravessar toda tese e produção de consenso público para regimes democráticos. Conclui-se pela convergência dos métodos estudados.

Palavras-chave: esquiva, consenso, ceticismo, sobreposição, filosofia pública.

\section{THE RAWLSIAN AVOIDANCE METHOD AS A SKEPTICAL CONSENSUS}

\begin{abstract}
The article discusses John Rawls's avoidance method in The Juxtaposition of a Consensus in 1987. The center of our reading of the consensus argument informs the unjustified refusal of skepticism, the second objection. It is suggested that it can integrate overlapping consensus. It is wished to point to a fact known among skeptics: the method of oppositions to the discussion sets up an ethics of the public for the public. It is described how the phenomenal language can cross all thesis and production of public consensus for democratic regimes. It concludes by the convergence of the methods studied.
\end{abstract}

Keywords: avoidance, consensus, skepticism, overlap, public philosophy.

\section{INTRODUÇÃO}

A tradição cética aparece com força no trabalho de Kant, ainda que não seja a entrada hegemônica na sua obra. Por outro lado, sua contribuição ao trabalho de Rawls ainda é pouco explorada. Procura-se com esse estudo conectá-la de modo a entender o que pode ser produzido no grande campo da prática e da coordenação de conflitos. Não se lê o trabalho do neocontratualista como um trabalho cético propriamente dito ou mesmo disparado por ele, ao

\footnotetext{
* Doutor em Ciência Política - Teoria Política pela UFF. Professor Tempo Integral e Pesquisador do Programa Pesquisa Produtividade da UNESA. Fundador e coordenador do Laboratório John Rawls de Filosofia Pública e Ciência Política - http://ljrawls.com. Esse artigo se beneficiou do trabalho de Iniciação Científica de Gustavo Menezes. daltonfranco@gmail.com. Indexador: http://orcid.org/0000-0003-3073-9060
} 
contrário, procura-se dar sentido prático ao ceticismo no bojo da procura por consenso. Mais relevante que apontar problemas internos na obra com esse artigo, procura-se tornar o argumento ainda mais preciso com a colaboração da escola de Sexto Empírico. A sobreposição de consensos está bastante antecipada entre os céticos, escolhe-se aqui um dos mais qualificados, Sexto Empírico, mas esse trabalho poderia ser ainda feito através de Kant. Os céticos não fundam propriamente um estado, não procuram um modelo de estado, nem um modo de governo, mas procuram um modo de vida que pode ser perfeitamente lido por um estado democrático de direitos habitado pela diferença, dissenso e conflito, cuja tônica é a primazia da vida tranquila. Nesse aspecto, observá-los em detalhes, em nuances e através da tradição contratual pode tornar o modelo rawlsiano ainda mais atual para a discussão da vida e da razão pública.

\section{CONSENSO SOBREPOSTO}

As teorias democráticas, contemporâneas (AVRITZER, 2000, p. 32) ou clássicas (BOBBIO, 1994 e 2001), devem ter algum diálogo com John Rawls, seja em Uma teoria da justiça (2008), em Justiça e democracia (2002) e em O liberalismo politico (2016) ${ }^{\dagger}$. A despeito da crítica específica (ZANITERLLI, 2012, p. 92) e da discussão mais geral (OLIVEIRA, 2015, p. 126), a tese de consenso sobreposto, que atravessa as três obras, pode ser lida como um dos produtos mais acabados da teoria rawlsiana em direção à vida de regimes constitucionais democráticos (RAWLS, 2008, p. 717). Nessa seção do trabalho, desejamos apenas descrevê-la em seus aspectos mais essenciais e em seguida discutir a segunda objeção, criada e recusada por ele, que ventila a possibilidade de seu consenso entoar indiferença e ou ceticismo à verdade e à inteireza de doutrinas abrangentes.

Se é bastante conhecida a influência kantiana no seu trabalho (RAWLS, 2008, p. 13), talvez não seja o trato cético aparente em sua obra no que chama de "método de esquiva". Quanto e quais ceticismos saem de Kant para abastecê-lo e quais são de Rawls será uma obra intertextual a ser realizada, por ora, com apoio de $T J$ e $J D$, nos ocuparemos de destacar centralmente como ele é usado no artigo "A ideia de um consenso por justaposição", de 1987, e sugerir como poderia ser acolhido.

\footnotetext{
$\dagger$ Cito Uma teoria da justiça como TJ e Justiça e democracia como JD.
} 
A imagem que antecede ao consenso sobreposto pode ser extraída do conhecido véu de ignorância (RAWLS, 2008, p. 165). Na posição original, momento de discussão dos princípios contratuais de uma sociedade democrática, Rawls pergunta como nos colocar de acordo, de modo equilibrado, senão de modo isonômico, e, de onde, como solução, indica um certo recolhimento e certa mutilação de informações contingentes que, potencialmente, nos fariam escolher princípios que não nos favorecessem imediatamente, mas que por outro lado favoreceriam a justiça social. Se ignorássemos nossa posição e status numa sociedade, se usássemos o véu de ignorância, a grande questão colocada nesse momento seria então quais princípios de justiça selecionaríamos (RAWLS, 2008, p. 697).

Um passo adiante, em $J D$, a abordagem ganha um pouco mais de empiria, ao concluir que temos um conjunto disparatado de conhecimento sobre o mundo social e isso afeta a maneira como recrutamos princípios de justiça; essa releitura aponta, sem rodeios, a conclusão para o que chamamos de vida sem véu. A partir de então começa o trabalho de definição e busca de um consenso sobreposto de $J D$.

Em Rawls, um consenso por justaposição ${ }^{\ddagger}$ deve possuir três pilares básicos: deve ser aplicado à estrutura básica da sociedade; não deve ser uma doutrina geral e abrangente; e deve ser parte das intuições sociais consolidadas a partir das experiências democráticas. Pelo primeiro, (a) refere-se ao "modo como as principais instituições sociais distribuem os direitos e os deveres fundamentais e determinam a divisão das vantagens decorrentes da cooperação social" (RAWLS, 2008, p. 8), qualquer consenso exequível deve ser tomado em obediência ao conjunto de atividades ocorridas nas instituições econômicas, sociais e políticas de uma sociedade, em última análise, deve ser aplicado à vida institucional existente (RAWLS, 2002, p. 249). Em seguida, (b) esse consenso não pode ser reclamado pelo predomínio de uma doutrina geral, que se refira a uma multiplicidade de temas, e sequer abrangente, que não possua uma leitura particular como "quando compreende concepções daquilo que constitui o valor da vida humana, ideias da virtude pessoal e do caráter" (RAWLS, 2002, p. 250), caso contrário há no piso da experiência social o que chama de "uso tirânico do poder do Estado" (RAWLS, 2002, p. 252). Finalmente, (c) esse consenso deve sair do juízo comum, da "convicção do senso comum" (RAWLS, 2008, p. 723) de uma determinada experiência social lastreada em democracias constitucionais, deve ser oriundo do que chama de "intuições fundamentais latentes no seio da cultura política pública”. Rawls afirma, já com certa leitura de ceticismo

\footnotetext{
¥ Cito "consenso", “consenso sobreposto", "consenso por justaposição" e "consenso rawlsiano" como sinônimos.
} 
negativo, "não haver visão geral e abrangente que possa fornecer fundamento público aceitável para uma concepção política da justiça” (RAWLS, 2002, p. 251, 255).

\subsection{Tópicos de consenso por traços de ceticismo}

Os três pilares devem passar pelo crivo do tempo, perdurar entre gerações, de uma a outra, para escaparem de ser o que é tratado por Rawls como modus vivendi, a sua primeira objeção formulada contra o próprio trabalho, para provar que o consenso não é um acidente efêmero, pois indica que ele pode e deve ser estável, deve unir o dissenso (RAWLS, 2002, p. 263). Esse ponto é o primeiro experimento, no artigo A ideia de um consenso por superposição, que exige certa auto avaliação seriada, a qual chamará de objeções. A primeira quer indicar que o seu consenso, preenchido pelas características apresentadas, é sólido, e que passa pela crítica da contingência (RAWLS, 2002, p. 263).

O exercício de pensar as bases do próprio trabalho, sua natureza e extensão são um compromisso ordinário que está presente ou que deve estar em qualquer trabalho generalizante como o de Rawls, esteve com Hobbes (2014), em o Leviatã, e com Kant (2015) desperto de seu sono dogmático por Hume $(2013 ; 1995)$. Seja o tratadista versado ou não nas bases do ceticismo de Sexto Empírico, referência obrigatória de acesso ao ceticismo antigo, um traço de seu trabalho é a abertura para a dúvida sistemática. Duas passagens conclusivas de $T J$ podem ajudar a flagrar alguns desses momentos.

Não procedi, então, como se os princípios primeiros, ou condições, ou definições, tivessem características especiais que lhes permitissem um lugar peculiar na justificação de uma doutrina moral (2008, p. 714). Negrito.

Mesmo que a argumentação que propus esteja correta, ela só demonstra que uma teoria que por fim seja adequada (caso exista) será mais parecida com a visão contratualista do que com quaisquer das outras doutrinas analisadas. E nem mesmo essa conclusão foi comprovada (2008, p. 717). Negrito.

Os traços de ceticismo são tácitos, são expressões de humildade intelectual, mais do que declaração de tempo de leitura da tradição cética, e um pouco mais de noção dos limites de qualquer teoria moral. Rawls sabe que a diversidade é um traço humano, reconhece que "não se pode definir a função de princípios morais de uma única forma; isso admite diversas interpretações" (RAWLS, 2008, p. 719). Isso introduz duas constatações: (d) o fato e a permanência do pluralismo em democracias constitucionais (RAWLS, 2002, p. 251-252, 255). Com risco de pleonasmo, isso descreve que, desde o que ele chama de grande cisma moral, 
católicos contra protestantes, a trajetória das sociedades de regimes constitucionais é marcada pelo fato das ideias frequentemente e desejavelmente estarem em desacordo, vivemos o estímulo da diferença e somos amparados por algumas ideias compartilhadas, corporificadas em instituições (RAWLS, 2002, p. 256) e por uma "linguagem da cultura política pública" (RAWLS, 2002, p. 257) fruto de um "fundo de ideias e de princípios fundamentais implicitamente compartidos" (RAWLS, 2002, p. 256).

\subsection{A recusa infundada ao ceticismo}

O fato do pluralismo convoca para a linha de frente do raciocínio a indecidibilidade e a falibilidade eventual da razão. Nesse aspecto, a (a) aplicabilidade, a lembrança clara da estrutura básica, a (b) recusa de uma doutrina geral e abrangente e, especialmente, a (c) linguagem de senso comum associada à (d) permanência do pluralismo podem sugerir, de fato, tal como objeta no artigo, que ele pode ser um cético negativo, e ou indiferente a qualquer vantagem superior em qualquer sorte de doutrina que rivaliza com a sua justiça como equidade. O consenso e o pluralismo apresentados sugerem ceticismo, mesmo que negue. O ceticismo é uma tradição que inclui ao menos três formas de representação: um ceticismo negativo, onde nenhuma verdade é possível, um probabilístico, no qual alguma verdade é provável, e um terceiro, o pirroniano, aquele que não acredita e nem recusa crença na existência de verdade essencial em qualquer concepção racional (BROCHARD, 2009). Por outro lado, com relação à indiferença, estamos supondo que ela corresponde, em $J D$, à crença em igual possibilidade de haver a verdade em (a) todas, em (b) nenhuma ou em (c) algumas das doutrinas gerais e abrangentes presentes na sociedade. Da mesma forma, afirmar que nenhuma doutrina geral e abrangente pode presidir um consenso e, ao mesmo tempo, produzir uma imagem de consenso que as acolha implica em indiferença, significa apontar que toda e qualquer uma pode conviver debaixo de um consenso maior.

Assim chegamos então à Segunda Objeção, a sua afirmação de que não é cético e nem indiferente à ideia de que uma doutrina geral e abrangente pode concorrer, e vencer, no concurso das doutrinas persuasivas, em regimes democráticos, sem estarem apoiadas num Estado tirânico. Defende-se do ceticismo com energia desnecessária, esse é o ponto principal a ser apresentado, pois ele, se bem considerado, pode fazer a objeção desaparecer, conforme sugerese. Ao mesmo tempo, defendemos que o seu consenso não implica linearmente em ceticismo negativo, e que não consegue “evitar as questões mais problemáticas” (RAWLS, 2002, p. 258); 
que seu consenso, pelo contrário, nasce acidentalmente do (i) modo de vida cético, saiba Rawls dessa informação ou não, seu trabalho é (ii) uma expressão dogmática indiferente às "verdades religiosas, filosóficas ou morais" (RAWLS, 2002, p. 252) e uma imagem oriunda de um (iii) senso cético ordinário.

Segue o centro da segunda objeção e da recusa ao ceticismo.

[Objeção] o fato de evitar doutrinas gerais e abrangentes implica indiferença ou o ceticismo com relação ao caráter de verdade de tal concepção. Evitar essas doutrinas pode parecer sugerir que uma concepção política poderia ser mais razoável para nós, mesmo quando ela fosse reconhecida como não verdadeira, como se a verdade aqui estivesse fora de propósito. [Réplica à objeção] A isso podese redarguir que é mais grave que uma concepção política seja cética ou indiferente em relação à verdade do que simplesmente estar em conflito com ela. Um ceticismo ou uma indiferença desse tipo colocaria a filosofia política em conflito com numerosas doutrinas abrangentes e comprometeria na base o seu objetivo de um consenso por justaposição. [Réplica cética] Aplicando esse 'método de esquiva', esforçamo-nos, tanto quanto possível, para não afirmar nem negar nenhuma opinião [Sexto Empírico] religiosa, filosófica ou moral, tampouco suas análises filosóficas da verdade e o status que elas atribuem a valores. Como pressupomos que cada cidadão defende uma opinião desse tipo, esperamos que seja possível para todos reconhecer uma concepção política como verdadeira ou razoável do ponto de vista da sua própria opinião abrangente, seja ela qual for [Apeles ${ }^{\S}$ ] (RAWLS, 2002, p. 267). Acréscimo, negrito e itálico.

Ainda nessa passagem, gostaríamos de discutir brevemente apenas a primeira parte, a Objeção propriamente dita. Em primeiro lugar, qualquer discussão sobre consenso não pode prescindir de algum conteúdo de verdade, de algum grau de candidatura sedutora. Em segundo lugar, o raciocínio pode conduzir a dois níveis de verdade, as verdades particulares, abaixo, e uma verdade geral, acima. Se Rawls crê que as doutrinas são, em alguma medida, verdadeiras, se ele não é cético e nem indiferente, para a hipótese de que se refere a duas coisas distintas, onde ceticismo e indiferença não são sinônimos, automaticamente não deixa de colocar, de sugerir a própria doutrina geral e abrangente, aquela que consegue refletir todas ao mesmo tempo, a parte central do sistema de cooperação social. Se ele não é, em primeiro lugar, indiferente, impõe contra si o fato de reconhecer alguma verdade nas outras proposições gerais e abrangentes. Se ele reconhece e sugere uma proposição que reconhece todas as que possuem alguma concepção verdadeira, põe-se acima delas. A estratégia verticaliza a verdade pondo a mais geral no alto, no centro, a que chama de consenso sobreposto, e as verdades parciais, ou as específicas demais, na parte de baixo. A verdade é propósito de qualquer concepção que reclame, que deseje e que procure a aderência de outras verdades doutrinárias subsidiárias. $\mathrm{O}$

\footnotetext{
$\S$ Alusão ao pintor grego, citado por Sexto Empírico em Outlines of Pyrrhonism, para quem a tranquilidade, a vida sem dogmas chegara por acidente; na menção, o pintor atinge o resultado feliz quando desiste da técnica e arremessa o pincel contra a tela e consegue o resultado (1933, p. 19).
} 
sentido da objeção e o consenso rawlsiano pode ser candidato numa competição de doutrinas que afirmam ser entre si a mais geral, a melhor concepção política de justiça e a de ser a mais abrangente.

Antes de passarmos pela Réplica à Objeção e pela Réplica cética, na próxima seção, recupera-se brevemente o que é uma filosofia política cética.

\section{A Filosofia Política Cética}

Os céticos e o ceticismo constituem uma tradição de pensamento criada na antiguidade. Sua obra, até então fragmentada, foi reunida principalmente por um médico do século I chamado Sexto Empírico e perdura até aqui. O centro da atividade cética consiste num conjunto de obstáculos a qualquer tentativa de assegurar a verdade por meio do expediente comum presente no movimento "aparência-essência" ou do interesse dogmático pela descoberta da essência das coisas em si. Sexto Empírico reuniu um conjunto de trabalhos de autores variados como Pirro, Enesidemo e Carnéades (BROCHARD, 2009). Hobbes, observado com bastante atenção por Rawls, não passou incólume à escola e "as soon as Hobbes published De Cive and Leviathan, he was accused of being a sceptic (POPKIN, 2003, p. 192). Ele tamém viveu debaixo de incertezas, "he lived in an intelectual society in which one of the sceptical doubts about man's ability to gain knowledge about the world" (POPKIN, 2003, p. 193). Sua operação possui desdobramento na vida pública (LOM, 2001).

Rawls não escreveu propriamente debaixo de um ambiente de certezas, viu conturbações similares às presenciadas por Hobbes e Sexto Empírico, o período antigo também teve o seu apogeu e declínio, especialmente com as quedas das Alexandrias. Sexto Empírico apenas deu um sistema ordenado para a dúvida profissional, empregada em boa medida até o presente (POPKIN, 2003). O centro da atividade cética informa alguns passos para o constrangimento dogmático: asserção, equipolência, suspensão do julgamento e a tranquilidade. Para um cético como Sexto Empírico, uma afirmação dogmática sobre a verdade pode ter uma construção perfeita e completamente persuasiva, mas um cético segue procurando (zetético) por asserções sobre o mesmo objeto; ao descobrir outra afirmação dogmática sobre a verdade assegurando a verdade perfeitamente persuasiva, o cético conclui pela equivalência entre uma e outra; decorre então que o cético tem iguais asserções, verdadeiras e persuasivas, de modo que lhe parece impossível assentir mais a uma que a outra, nesse momento, de indecidibilidade, ele suspende o juízo; que o motiva a seguir impassível com a pesquisa pela 
verdade, ao que, por acidente, lhe acontece a tranquilidade (ataraxia); portanto, do não assentimento a uma e a outra, decorre a imperturbabilidade ou o que chamam de taraqué ou de ataraxia (LESSA, 1995).

\subsection{A pesquisa cética ou o modo cético de dizer a filosofia política}

A pesquisa cética não tem pretensões definitivas sobre o mundo, ela não afirma como quem finaliza, determina e como quem define a natureza de um fenômeno ou objeto pesquisado. Sexto Empírico divide seu trabalho em duas partes, uma geral, de apresentação, e outra mais específica, a de objeções técnicas ao raciocínio dogmático, replicando e objetando caso a caso as escolas e as rotinas dogmáticas. Ainda na primeira parte do texto, duas passagens breves podem dar um pouco da dimensão do ceticismo de Sexto Empírico**:

(...) none of our future statements do we positively affirm that the fact is exactly as we state it, but we simply record each fact, like a chronicler, as it appears to us at the moment (SEXTO EMPÍRICO, 1933). Negrito.

Scepticism is an ability, or mental attitude, which opposes appearances to judgments in any way whatsoever, with the result that, owing to the equipollence of the objects and reasons thus opposed, we are brought firstly to a state of mental suspense and next to a state of 'unperturbedness' or quietude (SEXTO EMPÍRICO, 1933). Negrito.

Com a primeira, aprende-se que a afirmação cética do mundo não requisita terminar ou encerrar qualquer questão, de maneira que se comporta como um cronista, como quem fala do mundo como assim ele lhe aparece a um dado momento. Isso dá uma crônica não encerrada, motivada pela memória, e permanentemente vigilante aos ditames das necessidades de pesquisas que o mundo impõe ao juízo, das necessidades de dizermos o mundo (WOLF, 1999). Com a segunda, depreende-se o centro da operação de objetar a aparência de um mundo a outro. O método das oposições neutraliza a doença dogmática de afirmar o mundo por métodos idiossincráticos, ele convida o argumento e a representação a andarem em público. Sendo assim, o ceticismo consiste um método de discussão pública, ele não preenche o status de uma filosofia política doutrinária, pois não advoga uma visão específica ou, para glosar Rawls, um regime de governo. Suspender um juízo terminal sobre o mundo abre a possibilidade de um diálogo aberto sobre o que as aparências mostram, em lugar de revelar em privado o que é a real natureza dos fenômenos em perfeita análise esotérica.

\footnotetext{
** Ignora-se a regra habitual entre pesquisadores do ceticismo, nas qual se grafa a passagem por Livro, Parágrafo, seguido de Página do volume ou ainda como $H P, \mathrm{I}, 145$ ou $M, \mathrm{I}, 145$.
} 


\subsection{Objeção específica à organização da justiça de acordo com critérios dogmáticos}

Já na parte específica, nas objeções, o Décimo Argumento ou Décimo Tropo contra os dogmáticos é talvez o mais adequado à vida pública propriamente dita, aquele de avaliação da conduta prática, da ética pública. Nesse argumento, Sexto Empírico reúne Regras de Conduta, Hábitos, Leis, Crenças Lendárias, e Concepções dogmáticas (SEXTO EMPÍRICO, 1933, p. 85). Em lugar de afirmar o que é a ética universal, o comportamento correto, o argumento, pelo método das oposições, traz a discussão ética para o plano da decisão pública, de acordo com as aparências, de acordo com a capacidade pública de examinar o que seja a conduta adequada. $\mathrm{O}$ argumento junta os elementos numa cognição publicamente compartilhada, em lugar de uma ética última. A definição de cada uma delas em particular não sofre de anacronismo, sendo assim cada uma traz a mesma definição que se pratica em qualquer regime constitucional como, por exemplo, a definição de lei: "a law is a written contract amongst the memeber of a State, the transgressor of which is punished" (SEXTO EMPÍRICO, 1933, p. 87). A operação do método lembrará uma combinação caso a caso de cada um dos elementos de conduta praticados entre Estados diferentes, algo como: Regras no país, Regras noutro, regras e hábitos contra regras e hábitos e assim sucessivamente. Crê-se que o esquema pode dar a dimensão do que estamos tratando: RC1 - RC2, H1 - H2, L1 - L2, C1 - C2, L1 - L2, CD1 - CD2. Ou, simplesmente: Ética do Estado 1 versus Ética do Estado 2.

Com as objeções, Sexto Empírico deseja atingir a falta de fundamento público na afirmação da verdadeira ética pública pretensamente descoberta por um dogmático, de sorte que intenta mostrar equivalência entre as éticas, a não asserção a nenhuma delas em particular, e a vinda da tranquilidade oriunda da ausência do controle soberano do dogma sobre o mundo, de modo que conclui:

Only, since by means of this Mode also so much divergency is shown to exist in objects, we shall not be able to state what character belongs to the object in respect of its real essence, but only what belongs to it in respect of this particular rule of conduct, or law, or habit, and so on with each of the rest. So because of this Mode also we are compelled to suspend judgement regarding the real nature of external objects. And thus by means of all the Ten Modes [de objeção] we are finally led to suspension of judgment (SEXTO EMPÍRICO, 1933, p. 93). Negrito e acréscimo.

A ética cética aparece através da busca pela vida tranquila e também pela leitura reunida ou agrupada do Décimo Tropo, Montaigne fez isso de modo invulgar (ZALLOUA, 2005). Por ele ainda chega-se à filosofia política cética, uma montagem de estado mental e 
estatal sem a pretensão direta de instalar a priori um tipo de organização, de sistema e de processo de governo verdadeiros, mas conhecidos publicamente e da mesma forma cognoscíveis. Se fizermos uma leitura agregada da parte geral e da parte específica citados, pode-se apontar que: i) há um modo de vida praticado nesse Estado que diverge do praticado noutro, "so much divergency" (SEXTO EMPÍRICO, 1933, p. 93); ii) ambos são igualmente praticados e aceitos pelos seus habitantes; iii) apresentados a um cético, ambos possuem razões públicas para os aprovarem; iv) resta ao cético constatar a equivalência de consenso local e por isso "to suspend judgement” (SEXTO EMPÍRICO, 1933, p. 93) sobre o melhor, o mais correto ou o mais verdadeiro; v) disso resulta então a contínua investigação e a tranquilidade sobre a verdadeira forma de organizar uma determinada organização política de Estado, falta tempo de investigação, resta a quietude da alma.

De acordo com Sexto Empírico, uma filosofia política dogmática é intoxicada pela crença de que a sua razão possui conteúdo especial e que pode verter resultados especiais em relação à compreensão geral, à do mais ordinário dos homens. De outro modo, um dogmático é capaz de compreender e de revelar o verdadeiro e o falso, em pleno desacordo com as máximas protagóricas sobre a impossibilidade de conhecimento certo. A objeção ao conhecimento professoral é bem detalhada no livro Against Professors. A escola à qual se filia, a da tradição de Pirro, este o fundador do que chama-se pirronismo, que é a rigor um conjunto de práticas de compreensão e representação do mundo segundo as aparências em lugar do investimento nas essências, procura apenas falar do aparente, de maneira que todos podem ver e discutir por critérios lúcidos sobre o consenso, sem jogar indiferença contra o conhecimento da multidão. Uma vez filiado, objeta a possibilidade de conhecer e a de comunicar, a partir do método das objeções e da suspensão do julgamento. Sua crítica é dirigida especialmente sobre as Arts and Science, de onde saem eventualmente os sujeitos e os objetos filosóficos (SEXTO EMPÍRICO, 1949, p. 5).

As perguntas que Sexto Empírico faz aos dogmáticos giram em torno da impossibilidade de obter-se conhecimento e de oferta-lo, de como ensinar aquilo que não foi sequer apreendido. Por essa razão, se um professor não atingiu conhecimento, ele é um aluno, sendo assim, um aluno não ensina a outro, ou, por outro lado, o aluno ensina ao pretenso professor e ambos têm conhecimento diluído e comum:

(...) the non-expert cannot teach the non-expert, nor the expert the similar expert; for neiteher of these requires to learn, and this one has no more need of learning thant that one, nor that one than this one, both being equally full of knowledge (SEXTO EMPÍRICO, 1949, p. 21). 
Sequer a retórica, a arte da comunicação do conteúdo, para bons ou maus fins, esta salva da objeção cética. Se a arte do discurso não serve para resolver mostrar o verdadeiro e o falso, onde quer que grasse como primeiro veículo a revelar a verdade, ela produz danos irreparáveis: "if it is usfeful neither to its possessor nor to his neghbours, it will not be an art" (SEXTO EMPÍRICO, 1949, p. 211). A arte do discurso sequer é considerada uma arte, não constitui escola que escape de ser dogmática, pois por ela, pretensamente fornece-se a técnica esotérica correta para consensuar o real e o verdadeiro. Uma técnica esotérica não pode conduzir o mais comum dos homens, ele deve ser guiado pela discussão pública, por premissas, meios e resultados ao alcance de todos, ao alcance do mais ordinário senso dos homens (SEXTO EMPÍRICO, 1949). Em última análise, ainda de acordo com Sexto Empírico, se bem apresentado, o dogma pode impor ao mais comum dos homens uma severa derrota no estatuto jurídico de um Estado, venha por que meio vier, e mais perigosamente se inovar na infração da lei (SEXTO EMPÍRICO, 1949, p. 211). Na filosofia política aparente do ceticismo, não há lado doutrinário favorito, não há desejo de revelar aquilo que está inaparente, procura-se a conversa das coisas como aparecem, não como o que ocultam.

\section{O MÉTODO CÉTICO DE PRODUZIR CONSENSO SOBREPOSTO}

A partir de agora temos subsídios para trabalhar a Réplica à Segunda Objeção, onde Rawls afirma ser "mais grave que uma objeção seja cética ou indiferente à verdade do que simplesmente estar em conflito com ela" (RAWLS, 2002, p. 267). Ao contrário, nossa tese torna desejável que seja cética em relação à verdade, caso contrário, não atingirá a verdade pública, salvo a verdade privada, a dele mesmo e a de sua idiossincrática noção filosófica de consenso. Estuda-se a réplica com três hipóteses: que Rawls foi apenas impreciso quando fez a menção ao ceticismo, pois não sabia o que de fato trata o ceticismo; que fez uso dele como sinônimo de indiferença; e que fez menção precisa.

No primeiro caso, salva-se parte do raciocínio, mas macula-se o bojo da obra, pois não é grave que seja-se indiferente à verdade dogmática quando se procura consenso, é desejável e coerente em Sexto Empírico e na própria obra $J D$. Em seguida, aquela menos forte, a de uso de sinônimos, torna a combinação de ceticismo e indiferença quase impossível, pois indiferença e ceticismo são coisas bastante distintas, pois um cético discute em público, o indiferente não, vive de razão privada. Dentro da própria premissa rawlsiana, a indiferença é grave, o ceticismo 
não, é desejável. No terceiro caso, desmonta-se o raciocínio com a abordagem pirrônica, de maneira que a filosofia política cética não evita o conflito, não tem problema de estar imerso nele, de ser admoestada pelas filosofias, e muito menos ignora o seu resultado público. Em linguagem direta: sequer um ceticismo negativo seria aplicável, de modo que mesmo a recusa a reconhecer qualquer doutrina como verdadeira ou relevante traria dano à tese do cético como objetor de consensos sobrepostos, ele o convidaria. Diria um eventual cético destrutivo: nenhuma doutrina é capaz de encobrir todas as doutrinas, exceto a afirmação doutrinária negativa sobre todas as outras, isso derreteria a tese de consenso sobreposto de dentro para fora. Como corolário, temos que: ser cético não implica em dissenso sem consenso, pelo contrário, na acepção pirrônica, o ceticismo introduz a discussão e a razão públicas.

Quanto ao método de esquiva, ele pode ser renomeado e superado pelo método pirrônico, o método segundo o qual não se afirma e nem se nega nenhuma opinião, segundo o qual "none of our future statements do we positively affirm that the fact is exactly as we state it” (SEXTO EMPÍRICO, 1933, p. 5). Rawls afirma, por seu lado, ter se esforçado para não “afirmar nem negar nenhuma opinião" (RAWLS, 2002, p. 267) sobre doutrinas abrangentes e chama isso de esquiva. Seja como for, o emprego do método de esquiva significa algo como: não entrar na discussão particular e ater-se à discussão mais geral, significa buscar o consenso mais altivo e discutir apenas questões suficientemente gerais. Em primeiro lugar, a esquiva pura e simples do particular não credencia o consenso sobreposto como não particular e inatingível a outras doutrinas das doutrinas abrangentes. Poderíamos encontrar, em regressão infinita cética (SEXTO EMPÍRICO, 1933), algo como o consenso dos consensos sobrepostos e somente então considera-lo "aceitável para um grande leque de doutrinas abrangentes" (RAWLS, 2002, p. 258). Rawls deseja que a filosofia política dê as costas às querelas doutrinárias, "que a filosofia política tente permanecer, tanto quanto possível, independente e autônoma em relação aos outros segmentos da filosofia e, em especial, aos seus eternos problemas e às suas controvérsias" (RAWLS, 2002, p. 258), Sexto Empírico a quer no seio da discussão, no meio da multidão.

A terceira e última parte da objeção é derivada das outras duas: “que seja possível para todos reconhecer uma concepção política como verdadeira ou razoável do ponto de vista da sua própria opinião abrangente" (RAWLS, 2002, p. 267), com a exigência adicional de que concordem com uma opinião sobreposta baseada na sua própria sugestão. Esse acidente lembra o exercício de Apeles (SEXTO EMPÍRICO, 1933, p. 19), pois diz em outras palavras que: todas as opiniões abrangentes são viáveis, desejáveis e críveis; todas serão organizadas quando seus 
defensores desistirem de coloca-las acima da variedade delas, quando se colocarem lado a lado, ao mesmo tempo em que são capturadas por elementos superiores de um consenso acima das doutrinas particulares; nesse momento, como que por acidente, todos identificarão que o consenso superior pode coexistir ao lado das doutrinas particulares e ao mesmo tempo ser uma doutrina particularmente mais abrangente que todas as demais a guiar a vida, passaríamos da república para algo como "Estado, secularização e pluralismo", conforme Araújo (2013, p. 247). Sugere-se então que a terceira parte da segunda objeção é (i) um modo de vida cético, em lugar de uma assertiva meramente dogmática.

\subsection{O método de esquiva como consenso sobreposto}

A antecedência de Sexto Empírico em métodos de decisão não marca apenas um dado cronológico, sugere a coesão cética com a vida republicana e com os consensos de ambientes democráticos. Num inventário módico, sua obra antecipa: a razão pública; os métodos públicos; a visão compartilhada; o pluralismo doutrinário; a coexistência de linguagens; a falibilidade; a incorporação de métodos privados científicos quando escrutinados; os limites da razão e da idiossincrasia; e a tirania oriunda de um dogma que viole as regras de convivência estatais (SEXTO EMPÍRICO, 1933). Fixado o crédito da antecedência e da consistência teórica ao mundo cético, sobra para Rawls o papel autoral de ser indiferente às concepções particulares, então como corolário, seu trabalho nos aparece como (ii) uma expressão dogmática indiferente às verdades particulares. Rawls interroga como quem limpa o campo para passar a tese mais geral: "qual é o mínimo [de doutrina] que deve ser defendido? Se deve ser defendido, qual é a forma menos discutível?" (RAWLS, 2002, p. 259). A pergunta afirma que o mínimo para o geral ser alcançado como o melhor meio de atingir o consenso, numa espécie de expressão de mínimos consensuais consistentes, "para os quais convergem num consenso as doutrinas abrangentes" (RAWLS, 2002, p. 261). Ao tentar afirmar uma "razão pública livre" (RAWLS, 2008, p. 259), não produz mais que idiossincrasias anacrônicas e completamente antecipadas.

Eventualmente, há momentos onde abertamente podemos reconhecer uma potencial rota de pesquisa sobre a qualidade de ceticismo que atingiu Rawls, por exemplo, quando afirma a necessidade de "recorrer aos métodos comuns e ao conhecimento público disponível ao senso comum, bem como aos procedimentos e conclusões da ciência quando estas não são discutíveis" (RAWLS, 2002, p. 259). Por outro lado, acusamos a reiterada recusa da escola de Pirro: 
O reconhecimento desse limite (...) não se deve a um ceticismo ou a uma indiferença em relação às reinvindicações das doutrinas abrangentes, mas antes ao 'fato do pluralismo', na medida em que este significa que, numa sociedade pluralista, a livre razão pública não pode efetivamente ser reconhecida de nenhuma outra maneira (RAWLS, 2002, p. 260). Negrito

À parte uma parcela da discussão intertextual, o que a passagem indica é uma concepção que chamamos de (iii) um senso cético ordinário - com isso, preliminarmente, deseja-se indicar que o ceticismo o atinge por acidente, e não através do resultado de uma leitura diligente do mundo antigo ou de Kant e Hume. Os limites da razão privada devem-se a um ceticismo em relação ao particular como o vitorioso sobre o geral, e o fato do pluralismo é um diagnóstico claramente cético, trata-se de um mundo notadamente habitado por um diagnóstico pirrônico, no qual todas as asserções sobre o fenômeno e o real são bem vindas; da mesma maneira, a pesquisa zetética suspende o juízo sobre as imagens privadas. A passagem, se ajustada ao domínio da filosofia cética, pode colaborar com o consenso, em vez de deteriorálo.

\section{CONCLUSÃO}

Rawls não é infenso ao mundo cético. O que requisita mais atenção é quanto e quais ceticismos podem ser assumidos no trabalho como traço claro e meditado e quanto e quais podem ser, conforme sugere-se, mero acidente de dúvida numa obra de ênfase dogmática, como as três estudadas e em particular JD. A recusa ao ceticismo nos parece atentar contra as bases da tese central do artigo discutido, segundo nossa interpretação. Se é elogiável o método das objeções, mais que o de esquiva, mal encaixado, por outro lado seu trabalho demostra indiferença e um ceticismo mal debatido e negligenciado no argumento que busca o consenso. Buscá-lo sem o ceticismo, tal como está, indica um desconhecimento reprovável, até aqui insondado.

O sentido que fornecemos ao raciocínio expressa um meio de vida cético, um dogma de indiferença e um senso bastante ordinário do que seja o ceticismo, todos eles incompatíveis com o conjunto da obra. $\mathrm{O}$ argumento do consenso sobreposto, negligente e impreciso, é menos persuasivo. Estamos tratando então de uma indiferença e de uma hipertrofia do alcance do consenso sobreposto, ao mesmo tempo estamos tratando de um ceticismo negativo cuja perícia é incompatível com o bojo de JD. 
Desse modo, a filosofia política trazida por Sexto Empírico não somente é coerente com a produção de consensos em regimes constitucionais democráticos, ambiente do sentido de consenso rawlsiano, como também é desejável como nexo angular de coordenação do raciocínio. O método de oposições e a afirmação tácita e a tática da vida de acordo com o fenômeno social examinado em público indica certa anterioridade aos pirrônicos e completude ao raciocínio de Rawls.

Sugere-se, em terceiro lugar, que o método de esquiva pode ser lido como um derivado cético, acatado por acidente, tal como se descobre um resultado no caso de Apeles, um método que se confunde com o centro da atividade cética, a de não afirmar e nem negar peremptoriamente o verdadeiro e o falso e, com isso, buscar a vida comum, estável através, de parâmetros de compreensão baseados no mais comum dos homens. Esse caminho, da vida discutida em público para o público, configura uma filosofia pública e uma filosofia política. $\mathrm{O}$ fato e a manutenção do pluralismo, de modo análogo, são chamados de diafonia por Sexto Empírico, em que pese um certo anacronismo, num paralelismo que completa e abona o raciocínio do consenso mediado pela moderação. Se sabemos que o pluralismo/diafonia é um fato compartilhado publicamente, um resultado esperado é uma vida de tolerância e de moderação em relação à divergência e à diferença.

\section{REFERÊNCIA BIBLIOGRÁFICA}

-ARAJÚJO, Cícero Romão Resende de. A forma republicana: da constituição mista ao Estado. São Paulo: Editora WMF Martins Fontes, 2013.

-AVRITZER, Leonardo. Teoria democrática e deliberação pública. Lua Nova, Revista de Cultura e Política, 2000, $\mathrm{n}^{\circ}$ 50. Faces da democracia.

-BOBBIO, Norberto. Liberalismo e democracia. São Paulo: Brasiliense, 1994.

2001

. Estado, governo, sociedade: por uma teoria geral da política. São Paulo: Paz e Terra,

-BROCHARD, Vitor. Os céticos gregos. São Paulo: Odysseus Editora, 2009.

-LAVALLE, Adrián Gurza. A humildade do universal: Habermas no espelho de Rawls. Lua Nova, Revista de Cultura e Política, 1997, nº 42. Constituição.

-DE VITA, Álvaro; BORON, Atilio B (org). Teoria e Filosofia Política: a recuperação dos clássicos no debate Latino-americano. São Paulo: Edusp, 2004.

-HOBBES, Thomas. O leviatã. São Paulo: Martin Claret, 2014. 
. Os elementos da lei natural e política. São Paulo: WMF Martins Fontes, 2010.

-HUME, David. Uma investigação sobre os princípios da moral. Campinas: Editora da Unicamp, 2013.

. An enquiry concerning human understanding. Buffalo: Prometheus Books, 1988.

-LESSA, Renato. Veneno pirrônico: ensaios sobre o ceticismo. Rio de Janeiro: Francisco Alves, 1995.

-LOM, Petr. The limits of doubt: the moral and political implications of skepticism. New York: State University of New York Press, 2001.

-OLIVEIRA, Cícero. Justiça e equidade em John Rawls. Cadernos de Ética e Filosofia Política, São Paulo, Número 27, Página 114-128, 2015.

-POPKIN, Richard. The history of scepticism: from Savonarola to Bayle. New York, Oxford University Press, 2003.

-___ História do ceticismo: de Erasmo a Spinoza. Rio de Janeiro: Francisco Alves, 2000.

-RAWLS, John. Uma teoria da justiça. São Paulo: Martins Fontes, 2008.

-__ _ Justiça e democracia. São Paulo: Martins Fontes, 2002.

-___ _ O liberalismo político. São Paulo: WMF Martins Fontes, 2016.

___ C Conferências sobre a história da filosofia. São Paulo: WMF Martins Fontes, 2012.

-___ A theory of justice. Cambridge: Harvard University Press, 2003.

-SEXTO EMPÍRICO. Outlines of Pyrrhonism. Cambridge: Harvard University Press, 1933.

_____ Against Professors. Cambridge: Harvard University Press, 1949.

-SMITH, Plínio Junqueira. O ceticismo de Hume. São Paulo: Loyola, 1995.

-KANT, Immanuel. Crítica da razão pura. Petrópolis: Editora Vozes, 2015.

-__ C Crítica da razão prática. São Paulo: Folha de S. Paulo, 2015.

-WOLFF, Francis. Dizer o mundo. São Paulo: Discurso Editorial, 1999. Trad. Alberto Alonso Muñoz.

-ZALLOUA, Zahi. Montaigne and the ethics of skepticism. Charlottesville: Rookwood Press, 2005.

-ZANITELLI, Leandro Martins. A crítica de Cohen ao rawlsianismo e os problemas da liberdade ocupacional e da eficiência. Cadernos de Ética e Filosofia Política, São Paulo, Número 25, Página 90-107, 2012. 